\title{
PENGARUH PELATIHAN DAN PENGEMBANGAN TERHADAP DISIPLIN KERJA DAN KINERJA KARYAWAN
}

\author{
Sulaefi ${ }^{*}$ \\ ${ }^{1}$ Pascasarjana, Universitas Muhammadiyah Yogyakarta \\ *sulaefi2005@yahoo.co.id
}

\begin{abstract}
:
Training and development of human resources is necessary for organization to improve work discipline and performance. The purpose of this study are to analyze the influence of training and human resource development to the work discipline and performance, the affect of work discipline on performance as well as to determine the affect of training and development to the performance through work discipline. Respondents in this study are 80 employees College of Agricultural Extension (STPP) in Magelang. Analysis tools use descriptive, regression and path analysis. Results of this study shows that the training and development has an affect on the work discipline and performance. Training directly affects to the performance, while the development indirectly affects to the performance. The development affects to the performance through work discipline.
\end{abstract}

Keywords: Training and development, work discipline, performance.

\section{PENDAHULUAN}

Bisnis merupakan aspek kehidupan yang dinamis, oleh karena itu perusahaan yang ingin sukses dan unggul harus mampu mengantisipasi dan mengadaptasi setiap perubahan lingkungan bisnis dengan memberikan respon secara cepat dan tepat atau secara efektif dan efisien (Nawawi, (2005). Pencapaian tujuan organisasi tergantung pada kinerja karyawannya. Jika sebuah perusahaan menginginkan keunggulan bersaing melalui sumber daya manusia (SDM), maka harus memuat konsep pelatihan dan pengembangan SDM secara kontinyu. Pelatihan dan pengembangan sangat penting bagi karyawan dan organisasi agar lebih efektif (Devi \& Shaik, 2012). Dalam prakteknya keberhasilan bisnis berdasarkan pada standar kinerja yang tinggi dan hal ini tergantung pada sumber daya manusianya (Guest, 2011). Untuk itu manajemen puncak perlu menyadari pentingnya program pelatihan dan pengembangan dalam rangka peningkatan kinerja karyawannya. Perusahaan perlu mengelola program pelatihan lebih efektif agar mendapatkan banyak manfaat. Hal ini diperlukan karena peningkatan kemampuan, pengetahuan, dan keterampilan karyawan berbakat terbukti menjadi sumber keunggulan kompetitif (Ronald, 2006). Konsep tersebut tidak bisa dipungkiri bagi yang ingin menjadikan SDM sebagai sumber keunggulan kompetitif. Pelatihan dan pengembangan merupakan alat strategis yang sangat diperlukan untuk meningkatkan kinerja karyawan dan organisasi. Untuk itu anggaran untuk pelatihan tiap tahunnya perlu ditingkatkan, karena dipercaya akan mendapatkan keungulan kompetitif (Tjahjono, 2005; Falola, et.al, 2014).

Berdasarkan informasi dari media televisi dan surat kabar, Indonesia selalu mengalami kekurangan persediaan sumber daya manusia sebagai penyedia atau produsen, peneliti maupun sebagai penyuluh 
mengenai hewan ternak sapi guna memenuhi kebutuhan dalam negeri. Setiap tahun, selalu mengimpor sapi potong dalam jumlah yang banyak. Padahal Indonesia sebagai negara agraris banyak daerah penghasil sapi. Untuk memacu produksi sapi potong maka perlu mengkaji suatu lembaga pendidikan Sekolah Tinggi Penyuluhan Peternakan (STPP) Magelang agar dapat mencapai tujuan organisasi atau negara agar dapat swasembada sapi. Untuk itu perlu mengevaluasi peran dari pelatihan, pengembangan, disiplin kerja dan kinerja dari lembaga penyuluhan sapi tersebut. Kebetulan lembaga ini belum pernah melakukan penelitian yang menyangkut manajemen sumber daya manusia yang berhubungan, terutama masalah pelatihan dan pengembangan dengan masalah persapian potong tersebut untuk dapat lebih memacu tujuan perusahaan atau negara Indonesia dalam swasembada persapian potong tersebut.

Pelatihan adalah proses di mana orangorang mencapai kemampuan tertentu untuk membantu mencapai tujuan organisasi. Pelatihan lebih cenderung berorientasi jangka pendek, pelatihan berpengaruh pada kinerja, dan jika pelatihan yang dilakukan oleh perusahaan berhasil maka kinerja karyawan akan meningkat dengan sendirinya (Dessler, 2005). Karyawan merupakan aset yang berharga bagi perusahaan, tanpa pelatihan yang tepat, kepuasan pelanggan dan kualitas produk bisa kurang optimal. Karyawan yang menjalani pelatihan yang tepat cenderung mempertahankan pekerjaan mereka lebih lama. Efektivitas program pelatihan mengarah pada pengembalian investasi dan penelitian lainnya menyebutkan peran positif dari pelatihan adalah dapat mencapai tingkat retensi tertinggi. Manajer mencoba untuk mengembangkan kemampuan karyawan, akhirnya menciptakan lingkungan kerja yang lebih baik dalam organisasi. Program pelatihan yang efektif akan membantu karyawan untuk mendapatkan kemajuan baru sesuai yang diinginkan. Dengan program pelatihan juga mendapatkan kompetensi dan ketrampilan yang dibutuhkan dan untuk mengurangi kesalahan dalam bekerja (Dessler, 2005).

Sedangkan pengembangan adalah cangan pembelajaran untuk membantu pertumbuhan karyawan, memperbaiki kinerja karyawan pada pekerjaan mereka untuk memperbaiki posisi karyawan di masa yang akan datang (Tjeng, et.al, 2013). Pengembangan biasanya berkaitan dengan peningkatan kemampuan intelektual atau emosional yang diperlukan untuk melaksanakan pekerjaan yang lebih baik. Kebutuhan tenaga-tenaga terampil didalam berbagai bidang sudah merupakan tuntutan global yang tidak dapat di tunda lagi (Soss, et.al.2011). Dimasa seperti sekarang ini, dituntut untuk memiliki kemampuan dalam membuat rencana pengembangan sumber daya manusia yang berkualitas. Dalam upaya ini, manajemen suatu perusahaan dapat melakukan perbaikan, yang salah satunya melalui pengembangan SDM. Pelatihan dan pengembangan akan sangat membantu meningkatkan kompetensi yang difokuskan pada pengetahuan, keterampilan dan atau kemampuan. Perubahan yang paling jelas dalam pelatihan dan pengembangan adalah pergeseran untuk peningkatan kinerja dan penggunaan teknologi. Dengan demikian, keterampilan, pengetahuan dan kemampuan semakin diperlukan dalam pelaksanaan pelatihan dan pengembangan SDM (Berge, et.al., 2002).

Aspek manajemen lain yang mempengaruhi kinerja karyawan yaitu disiplin kerja. Disiplin kerja dalam suatu organisasi menjamin kinerja dan efisiensi (Chirasav, 2013). Seorang karyawan yang tingkat kedisiplinannya tinggi akan bekerja dengan lebih baik walaupun tanpa diawasi oleh atasan. Oleh karenanya, kedisiplinan karyawan perlu dilakukan penanganan secara lebih jelas karena pada dasarnya mencerminkan kinerjanya. Disiplin sangat penting dalam suatu perusahaan yang sehat dalam pencapaian tujuannya Disiplin merupakan bentuk pengendalian diri karyawan dan pelaksanaan yang teratur dan menunujukan tingkat kesungguhan tim kerja 
didalam sebuah organisasi. Tindakan disiplin yang efektif akan mendorong individu untuk meningkakan kinerja yang menguntungkan individu tersebut dan tentunya juga organisasi (Dessler, 2005). Disiplin dalam organisasi jika salah menafsirkan kejadiannya ketika gagal untuk menjelaskan maka bentuk pola sanksi juga akan gagal (Soss, et.al.,2011). Berdasarkan uraian di atas penelitian ini bertujuan untuk mengetahui seberapa besar pengaruh pelatihan dan pengembangan sumber daya manusia terhadap kinerja karyawan, menganalisis dan mengetahui efek dari pelatihan dan pengembangan terhadap disiplin kerja, untuk mengetahui pengaruh disiplin kerja terhadap kinerja karyawan, untuk mengetahui pengaruh tidak langsung pelatihan dan pengembangan terhadap kinerja karyawan melalui disiplin kerja.

\section{Tinjauan Pustaka \\ Kinerja Karyawan}

Menurut penelitian yang dilakukan oleh Suwarsih, (2005) menyatakan bahwa produktivitas karyawan menyoroti fakta bahwa karyawan yang puas dengan pekerjaan mereka akan memiliki prestasi kerja yang lebih tinggi, dan retensi terhadap pekerjaan demikian tinggi. Karyawan yang bahagia dan puas, memudahkan manajemen untuk memotivasi mereka berkinerja tinggi dalam mencapai target perusahaan (Kreitner \& Kinicki, 2007). Karyawan bisa puas bila merasa kompeten untuk melakukan pekerjaan, yang dicapai melalui program pelatihan yang lebih baik. Sebuah organisasi yang memberikan pengetahuan sebagai sumber mendapatkan keunggulan kompetitif dibandingkan pesaing, harus membangun sistem yang memastikan belajar terusmenerus dan melakukan pelathan secara efektif. Pfeffer (1994) menyoroti bahwa karyawan terlatif lebih mampu mencapai target kinerja dan mendapatkan keunggulan yang lebih kompetitif. Pelatihan ditentukan sebagai proses yang memungkinkan karyawan untuk dapat menyelesaikan tugas dengan efisiensi yang lebih besar, sehingga dianggap sebagai elemen penting dari pengelolaan sumber daya manusia strategis.

Tabel 1.

Hasil Penelitian Terdahulu Tentang Pelatihan dan Pengembangan SDM.

\begin{tabular}{|c|c|c|}
\hline No. & Nama Peneliti Terdahulu & Hasil Penelitiannya \\
\hline & $\mid \begin{array}{l}\text { Ameeq \& } \text { Hanif (2013) dalam } \\
\text { penelitianya yang berjudul “ } \\
\text { Impact of Training on } \\
\text { Employee's Development and } \\
\text { Performance in Hotel Industry of } \\
\text { Lahore, Pakistan “ }\end{array}$ & \begin{tabular}{|l} 
Karyawan sangat puas dengan \\
program pelatihan yang ada. Hasil \\
penelitian juga menunjukkan bahwa \\
$75 \%$ responden menyatakan \\
bahwa program pelatihan dapat \\
meningkatkan kinerja actual dan \\
membanturangembangkan \\
kemampuannya dan dapat bekerja \\
lebih efisien.
\end{tabular} \\
\hline & $\begin{array}{l}\text { Asad \& Mahfod (2015) dalam } \\
\text { penelitiannya yang berjudul “ } \\
\text { Training and Development and } \\
\text { Its Impact on the Employee's } \\
\text { Performance: A Study of Agility } \\
\text { Company-Kingdom of Bahrain } \\
\text { “. }\end{array}$ & $\begin{array}{l}\text { Ada hubungan positif langsung } \\
\text { antara pelatihan dan peningkatan } \\
\text { kinerja. Hasil positif tersebut } \\
\text { membuktikan bahwa pelatihan dan } \\
\text { pengembangan sangat penting bagi } \\
\text { organisasi untuk meningkatkan } \\
\text { kinerjanya dalam semua hal. } \\
\end{array}$ \\
\hline & $3 \mid \begin{array}{l}\text { Atan, Raghavan \& Mahmood } \\
\text { (2015) dalam penelitiannya yang } \\
\text { berjudul “ Impact of Training on } \\
\text { Employee's Job Performance: A } \\
\text { Case Study of Malaysian Small } \\
\text { Medium Enterprise “. }\end{array}$ & $\begin{array}{l}\text { Ada hubungan antara pelatihan } \\
\text { yang efektif dan kinerja karyawan. }\end{array}$ \\
\hline & $\begin{array}{l}\text { Diah \& Ajlouni (2015) dalam } \\
\text { penelitian tentang “ The Influence } \\
\text { of Training o Employee's } \\
\text { Performance, Organizational } \\
\text { Commitment and Quality of } \\
\text { Medical Service at Jordanian } \\
\text { Private Hospitals “. }\end{array}$ & $\begin{array}{l}\text { Ada hubungan yang kuat antara } \\
\text { komponen pelatihan terhadap } \\
\text { kinerja karyawan. Dan juga } \\
\text { pengaruh pelatihan karyawan } \\
\text { terhadap kualitas layanan medis dan } \\
\text { komitmen organisasi. Pengaruh } \\
\text { paling besar adalah pelatihan } \\
\text { karyawan dengan kualitas layanan } \\
\text { medis, dan pengaruh paling rendah } \\
\begin{array}{ll}\text { adalah terhadap komtmen } \\
\text { organisasi. }\end{array} \\
\end{array}$ \\
\hline & $\mid \begin{array}{l}\text { Falola, et.al. (2014) dalam } \\
\text { penelitian berjudul "Effectiveness } \\
\text { of Training and Development on } \\
\text { Employees Performance and } \\
\text { Organization Competitiveness in } \\
\text { The Nigerian Banking Industry “. }\end{array}$ & $\begin{array}{l}\text { Ada hubungan kuat antara pelatihan } \\
\text { dan pengembangan, } \\
\begin{array}{llr}\text { karyawan, } & \text { kinerja } \\
\text { kompetitif. } & & \text { keunggulan }\end{array}\end{array}$ \\
\hline & $\mid \begin{array}{lll}\text { Harlie } \quad(2012) & \text { dalam penelitian } \\
\text { dengan } & \text { judul “ } & \text { Pengaruh Disiplin } \\
\text { Kerja, Motivasi dan Pengambangan } \\
\text { Karier terhadap kinerja Karyawan } \\
\text { “. }\end{array}$ & $\begin{array}{|lrr|}\text { Disiplin } & \text { kerja, motivasi dan } \\
\text { pengembangan karier berpengaruh } & \\
\text { signifikan } & \text { terhadap } & \text { kinerja } \\
\text { karyawan. Dan disiplin kerja paling } \\
\text { dominan } & \text { pengaruhnya } & \text { terhadap } \\
\text { kinerja karyawan. }\end{array}$ \\
\hline & $\begin{array}{l}\text { Sultana et.al. (2012) dalam } \\
\text { penelitiannya berjudul “ Impact of } \\
\text { Training on } \begin{array}{lrr}\text { Employee } \\
\text { Performance: A } & \text { Study } & \text { of } \\
\text { Telecomunication } & \text { Sector } & \text { in } \\
\text { Pakistan “. } & \end{array}\end{array}$ & $\begin{array}{l}\text { Jika organisasi berinvestasi dalam } \\
\text { pelatihan karyawan adalah hal ang } \\
\text { sangat tepat karena pelatihan dapat } \\
\text { meningkatkan kinerja rana } \\
\text { kompetensi dan keahlian. Selain } \\
\text { itu, pelatihan dipandang sebagai } \\
\text { sarana mengatasi perubahan inovasi } \\
\text { teknologi, persaingan pasar, } \\
\text { struktur organisasi, dan yang paling } \\
\text { penting yaitu memainkan peran } \\
\text { kunci untuk meningkatkan kinerja } \\
\text { karyawan. }\end{array}$ \\
\hline & $\begin{array}{l}\text { Tahir, et.al. (2014) dakam } \\
\text { jurnalnya yang berjudul “ The } \\
\text { Impact of Training and } \\
\text { Development on Employess } \\
\text { Performance and Productivity: } \\
\text { A Case Study of United Bank } \\
\text { Limited Peshawar City, KPK, } \\
\text { Pakistan " }\end{array}$ & \begin{tabular}{|lrr} 
Ada & hubungan yang & signifikan \\
antara & pelatihan & dan \\
pengembangan, kinerja & dan \\
prodktivitas karyawan. &
\end{tabular} \\
\hline
\end{tabular}




\section{Pelatihan dan Pengembangan Sumber Daya Manusia}

Sims (2006) menekankan bahwa pelatihan yang berfokus pada pekerjaan saat sekarang sedangkan pengembangan berfokus mempersiapkan karyawan ke masa depan. Pelatihan menjembati kesenjangan antara kinerja saat ini dan standar yang diinginkan. Pelatihan dapat diberikan melalui metode yang berbeda seperti pada pembinaan dan monitoring, rekan-rekan kerja sama dan partisipasi oleh bawahan. Program pelatihan tidak hanya mengembangkan karyawan tetapi juga membantu organisasi untuk membuat penggunaan terbaik dan mendukung keunggulan kompetitif. Oleh karena itu perusahaan mempunyai kewajiban untuk merencanakan suatu program pelatihan bagi karyawan untuk meningkatkan kemampuan dan kompetensi mereka yang dibutuhkan di tempat kerja (Jie dan Roger, 2006). Pelatihan tidak hanya mengembangkan kemampuan karyawan tetapi juga mempertajam kemampuan berfikir dan kreativitas dalam rangka untuk mengambil keputusan yang lebih baik dalam waktu dan cara yang lebih produktif. Selain itu juga memungkinkan karyawan untuk berurusan dengan pelanggan secara efektif dan menanggapi keluhan mereka secara tepat waktu (Hollenbeck, Derue dan Guzzo, 2004). Pelatihan mengembangkan efikasi diri dan hasil kinerja superior pada pekerjaan, dengan mengganti praktek tradisional dengan praktek kerja terkait yang efisien dan efektif. Pelatihan mengacu pada intervensi yang direncanakan dan bertujuan untuk meningkatkan unsur-unsur kinerja individu (Chiaburu dan Tekleab, 2005). Program pelatihan juga dapat membantu tenaga kerja untuk mengurangi kecermasan atau frustasi mereka yang berasal dari pekerjaan (Chen, et.al., 2004). Menurut Rowden dan Conine (2005), karyawan yang terlatih lebih mampu untuk memuaskan pelanggan (Tsai, et.al., 2007), dan karyawan yang belajar sebagai hasil dari program pelatihan akan menunjukkan tingkat kinerja yang lebih besar dari kepuasan kerja bersama dengan kinerja yang unggul. Pengembangan karyawan merupakan suatu keharusan untuk menghadapi lingkungan bisnis saat ini. Pelatihan dan pengembangan yang tepat akan meningkatkan kinerja sehingga akan mewujudkan tenaga kerja yang efektif dan efisien.

\section{Disiplin Kerja}

Disiplin dalam suatu organisasi akan menjamin prodktivitas dan efisensi. Displin sebagai pendorong keharmonisan dan kerjasama antar karyawan dan bertindak sebagai pendorong moral untuk para karyawan. Manajemen disiplin kerja tetap menjadi masalah utama dalam hubungannya dengan karyawan dan merupakan sumber konflik di tempat kerja (Fenley, 1998). Mangkunegara (2013) mengemukakan bahwa "Dicipline is managemet action to enforce organization standards". Berdasarkan pendapat Mangkunegara (2013), disiplin kerja dapat diartikan sebagai pelaksanaan manajemen untuk memperteguh pedoman organisasi. Disiplin merupakan bentuk pengendalian diri karyawan dan pelaksanaan yang teratur dan menunjukan tingkat kesungguhan tim kerja didalam sebuah organisasi. Disiplin kerja tidak hanya akan meningkatkan perilaku karyawan tetapi juga akan meminimalkan masalah disiplin di masa depan melalui hubungan positif atasanbawahan (Engelbrecht, et.al., 2008). Tujuan utama dari disiplin kerja adalah untuk membantu karyawan memahami masalah kinerja atau kesempatan untuk perbaikan (Chien, 2004). Proses disiplin tidak dimaksudkan untuk menghukum seseorang tetapi membantu karyawan untuk masalah kinerja dan memenuhi harapan. Pemikiran tersebut menunjukkan bahwa ada sinergi antara disiplin dan kinerja perusahaan. Grote (1995), mengatakan bahwa organisasi harus memutuskan bahwa standar pekerjaan yang dikomunikasikan, karyawan mendapatkan umpan balik dari kinerja dan standar kerja yang dicapai. Kinerja organisasi sebagai kemampuan organisasi untuk mencapai tujuannya dengan menggunakan sumber daya manusia secara efisien dan efektif. 
Sementara disiplin diperlukan dalam banyak kesempatan.

\section{Hipotesis}

Berdasarkan hasil-hasil riset tersebut maka dalam penelitian ini menggunakan hipotesis sebagai berikut:

$\mathrm{H}_{1}$ :Diduga pelatihan berpengaruh signifikan terhadap disiplin kerja.

$\mathrm{H}_{2}$ :Diduga pengembangan berpengaruh signifikan terhadap disiplin kerja.

$\mathrm{H}_{3}$ :Diduga pelatihan dan pengembangan secara simultan berpengaruh signifikan terhadap disiplin kerja.

$\mathrm{H}_{4}$ :Diduga pelatihan berpengaruh signifikan terhadap kinerja karyawan.

$\mathrm{H}_{5}$ :Diduga pengembangan berpengaruh signifikan terhadap kinerja karyawan.

$\mathrm{H}_{6}$ :Diduga pelatihan dan pengembangan berpengaruh signifikan terhadap kinerja karyawan secara simultan.

$\mathrm{H}_{7}$ :Diduga disiplin kerja secara parsial berpengaruh signifikan terhadap kinerja karyawan.

$\mathrm{H}_{8}$ :Diduga pelatihan mempunyai pengaruh terhadap kinerja karyawan melalui disiplin kerja karyawan.

$\mathrm{H}_{9}$ :Diduga pengembangan mempunyai pengaruh terhadap kinerja karyawan melalui disiplin kerja karyawan.

\section{METODE}

Penelitian dilakukan di Sekolah Tinggi Penyuluhan Pertanian (STPP) Magelang yang beralamat di Jl. Magelang, Kopeng KM 7, Purwosari, Tegalrejo, Magelang 56192.. Penelitian dilakuan selama 3 bulan dari Maret 2016 sampai dengan Juni 2016.

Data yang digunakan dalam penelitian ini adalah data primer. Penelitian ini menggunakan pendekatan kuantitatif dengan metode survei dengan menggunakan disproportional random sampling dengan 80 responden dari populasi karyawan sebanyak 133 orang karyawan STPP (dengan rincian 22 orang dosen dan 111 karyawan). Pada awalnya menyebaran kuesioner sebanyak 100 responden tetapi pada tahap akhir survei hanya sekitar 80 responden yang terkumpul. Pernyataan-pernyataan dalam kuesioner dengan menggunakan skala Likert degan lima jenjang alternatif jawaban yaitu sangat setuju, setuju, ragu-ragu, tidak setuju, dan sangat tidak setuju. Hasil kuesioner dianalisis dengan metode kuantitatif. Analisis data menggunakan analisis regresi dan analisis jalur.

Pada penelitian ini ada tiga variabel penelitian yang digunakan yaitu pelatihan $\left(\mathrm{X}_{1}\right)$ dan pengembangan $\left(\mathrm{X}_{2}\right)$ sebagai variabel independen, kinerja karyawan (Y) sebagai variabel dependen, dan disiplin kerja sebagai variabel intervening ( $Z$ ) Berikut ini definisi operasioanal variabel penelitian pada tabel 2 berikut ini.

Tabel 2.

Definisi Operasional Variabel Penelitian

\begin{tabular}{|c|c|}
\hline $\begin{array}{c}\text { Variabel } \\
\text { Penelitian } \\
\end{array}$ & Dimensi \\
\hline $\begin{array}{l}\text { Independent } \\
\text { variabel }\left(X_{1}\right) \\
\text { Program Pelatihan } \\
\text { (Mangkunegara, } \\
\text { 2013) }\end{array}$ & $\begin{array}{l}\text { - Instruktur } \\
\text { - Peserta } \\
\text { - Materi } \\
\text { - Metode } \\
\text { - Tujuan } \\
\text { - Sasaran } \\
\end{array}$ \\
\hline $\begin{array}{l}\text { Independent } \\
\text { variabel }\left(\mathrm{X}_{2}\right) \\
\text { Program } \\
\text { Pengembangan } \\
\text { (Mangkunegara, } \\
\text { 2013) }\end{array}$ & $\begin{array}{ll}\text { - } & \text { Etode Pelatihan } \\
\text { - } & \text { Understudy } \\
\text { - Job Rotasi dan } & \text { kemajuan } \\
& \text { bersama } \\
\text { - } & \text { Coaching } \\
& \text { Counseling } \\
\end{array}$ \\
\hline $\begin{array}{l}\text { Intervening } \\
\text { variabel (Z) } \\
\text { Disiplin Kerja } \\
\text { (Rivai \& Basri, } \\
\text { 2005) }\end{array}$ & $\begin{array}{ll}\text { - } & \text { Kehadiran } \\
\text { - } & \text { Ketaatan pada } \\
& \text { peraturan kerja } \\
\text { - } & \text { Ketaatan pada } \\
& \text { standar kerja } \\
\text { - } & \text { Tingkat } \\
& \text { kewaspadaan } \\
& \text { tinggi } \\
\text { - } & \text { Bekerja etis }\end{array}$ \\
\hline $\begin{array}{l}\text { Dependent variabel } \\
\text { (Y) } \\
\text { Kinerja Karyawan } \\
\text { (Dessler, 2005) }\end{array}$ & $\begin{array}{ll}\text { - } & \text { Kualitas } \\
\text { - } & \text { Produktivitas } \\
\text { - } & \text { Pengetahuan } \\
& \text { mengenai } \\
& \text { pekerjaan } \\
\text { - Ketepercayaan } \\
\text { - Kebebasan }\end{array}$ \\
\hline
\end{tabular}




\section{Pengujian Validitas dan Reabilitas Instrumen}

Dari hasil olah data diketahui bahwa nilai sig. $>0.220$, sehingga seluruh pernyataan dalam kuesioner pada item-item pernyataan pada variabel pelatihan dan pengembangan SDM serta disiplin kerja adalah valid dan reliabel.

\section{HASIL}

Berdasarkan hasil penelitian yang telah dilakukan terhadap 80 responden, dapat diketahui bahwa responden dalam penelitian ini sebagian besar berjenis kelamin laki-laki dengan dengan 65 responden (81.25\%), dengan usia 40-50 tahun 26 responden (32.50\%), berpendidikan diploma (D3-D4) sebanyak 50 responden $(62.50 \%)$ dan sarjana 15 responden (18.75\%) dengan rincian sarjana S1 sebanyak 15 responen (12,50 \%) dan S2 sebanyak 5 responde ( 6.15 $\%)$ dan masa kerja kebanyakan lebih > 10 tahun sebanyak 40 responden (50 \%). Berdasarkan hasil penilaian rerata pelatihan sebesar 3.37 dan rerata pengembangan sebesar 3.17. Berdasarkan hasil analisis data karakteristik responden tersebut maka dapat dikatakan bahwa hal ini menunjukkan bahwa secara umum program penelitian ini dapat dipersepsikan baik.

\section{Uji Normalitas, Uji Multikolinearitas, dan Uji Heterokedastisitas}

Untuk menguji apakah dalam model regresi variabel dependen dan variabel independen mempunyai distribusi normal atau tidak diuji dengan menggunakan uji normalitas. Model regresi yang baik memiliki distribusi data normal atau mendekati normal (Ghozali, 2011). Dasar pengambilan keputusan adalah jika nilai probabilitas $>0.05$, maka model regresi memenuhi asumsi normalitas. Hasil uji normalitas dengan Kolmogorov Smirnov Test adalah sebagai berikut pada tabel 3 .
Tabel 3.

Hasil Uji Normalitas dengan Kolmogorov Smirnov Test

\begin{tabular}{lccl}
\hline Variabel & Sig. & $\begin{array}{c}\text { Nilai } \\
\text { Kritis }\end{array}$ & Keterangan \\
\hline Kinerja & 0.098 & 0.05 & Normal \\
Pelatihan & 0.072 & 0.05 & Normal \\
Pengembangan & 0.053 & 0.05 & Normal \\
Disiplin kerja & 0.074 & 0.05 & Normal \\
\hline \multicolumn{4}{l}{ Sumber : Hasil Uji Normalitas, 2016. }
\end{tabular}

Berdasarkan hasil uji normalitas dengan Kolmogorov Smirnov Test pada tabel 3 di atas terlihat nilai probabilitas $>0.05$, maka model regresi memenuhi asumsi normalitas.

Uji multikolinearitas merupakan keadaan dimana salah satu atau lebih variabel independen dapat dinyatakan sebagai kombinasi linear dari variabel independen lainnya. Salah satu asumsi regresi linier klasik adalah tidak adanya muliolineartas sempurna. Suatu model regresi ditakan terkena multikolinearitas apabila terjadi perfect atau exact diantara beberapa atau semua variabel bebas. Akibatnya akan sulit untuk melihat pengaruh secara individu variabel bebas terhadap variabel tak bebas. Pendeteksian multikolinearitas dalam penelitian ini dilakukan dengan metode VIF. Jika VIP > 10, maka H0 ditolak dan jika VIF $<10$, maka HO diterima. Hasil uji multikolinearitas dengan metode VIF tersebut dapat dilihat pada tabel 4 .

Tabel 4 .

Hasil Uji Multikolinearitas denagn Metode VIF

\begin{tabular}{cccc}
\hline Variabel & VIF & $\begin{array}{c}\text { Nilai } \\
\text { Kritis }\end{array}$ & Keterangan \\
\hline Pelatihan & 1.254 & 10 & $\begin{array}{l}\text { Tidak terkena } \\
\text { multikolinearit } \\
\text { as }\end{array}$
\end{tabular}

\begin{tabular}{lccl} 
Pengembangan & 1.458 & 10 & $\begin{array}{l}\text { Tidak terkena } \\
\text { multikolinearit } \\
\text { as }\end{array}$ \\
Disiplin kerja & 1.384 & 10 & $\begin{array}{l}\text { Tidak terkena } \\
\text { multikolinearit } \\
\text { as }\end{array}$ \\
\hline Sumber : Hasil Olah Data Uji VIF, 2016
\end{tabular}


Pendeteksian multikolinearitas dalam penelitian ini dilakukan dengan metode VIF. Jika VIF $>10$, maka $\mathrm{H}_{0}$ ditolak dan Pendeteksian multikolinearitas dalam penelitian ini dilakukan dengan metode jika VIF $<10$, maka $\mathrm{H}_{0}$ diterima. Hasil uji multikolinearitas dengan metode VIP adalah sebagai berikut pada tabel 4. Berdasarkan hasil uji multikolinearitas dengan metode VIF, nilai VIF $<10$, artinya bahwa semua variabel bebas tidak terjadi multikolinearitas, sehingga tidak membiaskan interprestasi hasil analisis regresi. Homoskedastisitas adalah situasi dimana varian $\left(\alpha^{2}\right)$ dari faktor pengganggu atau disturbance term adalah sama untuk semua observasi $X$. Penyimpangan terhadap asumsi ini yaitu disebut heteroskedastisitas yaitu apabila nilai varian $\left(\alpha^{2}\right)$ variabel tidak bebas (Y) meningkat sebagai akibat dari meningkatnya varian dari variabel bebas $\left(\mathrm{X}_{\mathrm{i}}\right)$, maka varian dari $\mathrm{Y}$ tidak sama. Pendeteksian heteroskedastisitas dalam penelitian ini dilakukan dengan metode Glejser. Caranya dengan melihat nilai probabilitas $>0.5$ sehingga tidak terkena heteroskedastisitas (Ghozali, 2011). Hasil uji heteroskedstisitas dengan Glejser sebagai berikut pada tabel 5 berikut ini.

Tabel 5.

Hasil Uji Heteroskadastistas dengan Glejser

\begin{tabular}{|c|c|c|c|}
\hline Variabel & Sig. & $\begin{array}{c}\text { Nilai } \\
\text { Kritis }\end{array}$ & Keterangan \\
\hline Pelatihan & 0.201 & 0.05 & $\begin{array}{l}\text { Homoskedas } \\
\text { tisitas }\end{array}$ \\
\hline Pengembangan & 0.213 & 0.05 & $\begin{array}{l}\text { Homoskedas } \\
\text { tisitas }\end{array}$ \\
\hline Disiplin kerja & 0.504 & 0.05 & $\begin{array}{l}\text { Homoskedas } \\
\text { tisitas }\end{array}$ \\
\hline Kinerja & 0.061 & 0.05 & $\begin{array}{l}\text { Homoskedas } \\
\text { tisitas }\end{array}$ \\
\hline
\end{tabular}

Sumber : Hasil Olah Data, 2016

Hasil uji heteroskedastisitas menunjukkan bahwa nilai probabilitas > 0.05. Hal ini berarti model yang diestimasi bebas dari heteroskadasitas.
Tabel 6.

Hasil Regresi Linier Pelatihan dan Pengembangan SDM terhadap Disiplin Kerja Karyawan STPP Magelang.

\begin{tabular}{llll}
\hline Variabel & $\begin{array}{l}\text { Koefisien } \\
\text { Beta }\end{array}$ & t-hitung & Probabilitas \\
\hline Konstanta & -0.123 & -0.226 & 0.821 \\
Pelatihan SDM $\left(\mathrm{X}_{1}\right)$ & 0.228 & 2.052 & 0.042 \\
Pengembangan SDM $\left(\mathrm{X}_{2}\right)$ & 0.425 & 3.822 & 0.000 \\
\hline $\mathrm{R}^{2}: 0.343$ & & & \\
Adjusted $^{2}: 0.325$ & & \\
$\mathrm{~F}$-statstic : $20.093 \mathrm{Sig}$ : $=0.000$ & & \\
$\mathrm{~N}: 80$ & & \\
Variabel Dependen (Z):Disiplin & & \\
Kerja Karyawan & & & \\
\hline
\end{tabular}

Sumber : Hasil Olah Data, 2016

Berdasarkan tabel 6 tersebut maka uji hipotesis pelatihan dan pengembangan SDM terhadap disiplin kerja karyawan STPP adalah sebagai berikut.

Pengujian pengaruh variabel pelatihan SDM $\left(\mathrm{X}_{1}\right)$ terhadap variabel disiplin kerja karyawan (Z) diperoleh nilai probabilitas t. hitung $(0.042)<$ Level of Significant (0.05), maka variabel pelatihan SDM $\left(\mathrm{X}_{1}\right)$ berpengaruh secara parsial terhadap disiplin kerja (Z) karyawan STPP Magelang.

Pengujian pengaruh variabel pengembangan SDM $\left(\mathrm{X}_{2}\right)$ terhadap variabel disiplin kerja karyawan (Z). diperoleh nilai probabilitas t-hitung $(0.000)<$ Level of Sgnificant (0.05), maka disimpulkan bahwa variabel pengembangan SDM $\left(\mathrm{X}_{2}\right)$ berpengaruh secara parsial terhadap disiplin kerja (Z) karyawan STPP Magelang.

Pengujian pengaruh variabel pelatihan $\operatorname{SDM}\left(\mathrm{X}_{1}\right)$ dan pengembangan SDM $\left(\mathrm{X}_{2}\right)$ secara simultan terhadap variabel disiplin kerja (Z) data diperoleh nilai probabilitas $F_{\text {. }}$ hitung $(0.000)<$ Level of Significant (0.05), maka variabel pelatihan SDM (X1) dan pengembangan SDM (X2) berpengaruh secara simultan terhadap disiplin kerja karyawan (Z) STPP Magelang. Untuk menguji hipotesis ke tujuh tentang secara parsial berpengaruh signifikan terhadap kinerja karyawan (Y) STPP Magelang, perlu pengolahan data dari hasil kuesioner dengan hasil seperti tercantum dalam tabel 7 berikut ini. 
Tabel 7.

Hasil Regresi Linier Disiplin Kerja terhadap Kinerja Karyawan

\begin{tabular}{lccc}
\hline \multicolumn{1}{c}{ Variabel } & $\begin{array}{c}\text { Koefisien } \\
\text { Beta }\end{array}$ & t-hitung & Probabilitas \\
\hline Konstanta & 0.667 & 3.013 & 0.002 \\
Disiplin Kerja (Z) & 0.788 & 11.352 & 0.000 \\
N : 80 & & & \\
Variabel Dependen (Y): & & \\
Kinerja Karyawan & & \\
Sumber : Hasil Olah Data, 2016 &
\end{tabular}

Pengujian pengaruh variabel disiplin kerja karyawan (Z) terhadap variabel kinerja karyawan $(\mathrm{Y})$ diperoleh nilai probabilitas $\mathrm{t}$. hitung $(0.000)<$ Level of Significant (0.05), maka disimpulkan bahwa variabel disiplin kerja (Z) karyawan berpengaruh secara parsial terhdap kinerja karyawan (Y) STPP Magelang.

Berikut ini hasil olah data variabel pelatihan SDM $\left(\mathrm{X}_{1}\right)$ dan pengembangan SDM $\left(\mathrm{X}_{2}\right)$ terhadap kinerja karyawan $(\mathrm{Y})$ dengan menggunakan analisis regresi ditunjukkan oleh tabel 8 berikut ini.

Tabel 8.

Hasil Regresi Pelatihan dan pengembangan terhadap Kinerja

\begin{tabular}{|c|c|c|c|}
\hline Variabel & $\begin{array}{c}\text { Koefísien } \\
\text { Beta }\end{array}$ & t-hitung & $\begin{array}{c}\text { Probabi } \\
\text { litas }\end{array}$ \\
\hline Konstanta & 0.503 & 0.887 & 0.376 \\
\hline Pelatihan $\operatorname{SDM}\left(\mathrm{X}_{1}\right)$ & 0.285 & 2.401 & 0.018 \\
\hline Pengembangan SDM $\left(\mathrm{X}_{2}\right)$ & 0.277 & 2.332 & 0.021 \\
\hline \multicolumn{4}{|l|}{$R^{2}: 0.248$} \\
\hline \multicolumn{4}{|l|}{ Adusted $\mathrm{R}^{2}: 0.229$} \\
\hline \multicolumn{4}{|l|}{ F-trainitik $: 12.718$ Sig $=0.000$} \\
\hline $\mathrm{N}: 80$ & & & \\
\hline Variabel Dependen $(\mathrm{Y})$ : Kinerja karyawan & & & \\
\hline
\end{tabular}

Sumber: Hasil Olah Data, 2016

Pengujian pengaruh variabel pelatihan SDM $\left(\mathrm{X}_{1}\right)$ terhadap variabel kinerja karyawan $(\mathrm{Y})$ diperoleh nilai probabilitas $\mathrm{t}$. hitung $(0.018)<$ Level of Significant (0.05), maka disimpulkan bahwa variabel pelatihan SDM $\left(\mathrm{X}_{1}\right)$ berpengaruh secara parsial terhadap kinerja karyawan (Y) STPP Magelang.

Pengujian pengaruh variabel pengembangan SDM $\left(\mathrm{X}_{2}\right)$ terhadap variabel kinerja karyawan (Y) diperoleh nilai probabilitas $t_{\text {-hitung }}(0.021)<$ Level of Significant (0.05), maka dapat disimpulakan bahwa variabel pengembangan SDM $\left(\mathrm{X}_{2}\right)$ berpengaruh secara parsial terhadap kinerja karyawan(Y) STPP Magelang.
Pengujian pengaruh variabel pelatihan $\operatorname{SDM}\left(\mathrm{X}_{1}\right)$ dan pengembangan SDM $\left(\mathrm{X}_{2}\right)$ secara simultan terhadap variabel kinerja karyawan (Y) diperoleh nilai probabilitas $\mathrm{F}$. hitung $(0.000)<$ Level of Significant (0.05), maka dapat disimpulkan bahwa variabel pelatihan SDM $\left(\mathrm{X}_{1}\right)$ dan pengembangan SDM $\left(\mathrm{X}_{2}\right)$ berpengaruh secara simultan terhadap kinerja karyawan (Y) STPP Magelang.

Rangkuman dari koefisien jalur pengaruh langsung, pengaruh tidak langsung, dan total dari pengaruh pelatihan $\operatorname{SDM}\left(\mathrm{X}_{1}\right)$, pengembangan $\operatorname{SDM}\left(\mathrm{X}_{2}\right)$, dan disiplin kerja (Z) terhadap kinerja (Y) dapat ditunjukkan pada tabel 9

Tabel 9.

Rangkuman Koefisien Jalur, Pengaruh Langsung dan Tidak Langsung

\begin{tabular}{lccc}
\hline Pengaruh Variabel & Langsung & Tldak Langsung melalui $(\mathrm{Z})$ & Total \\
\hline $\mathrm{X}_{1} \rightarrow \mathrm{Z}=0.228$ & 0.228 & 0 & 0.228 \\
$\mathrm{X}_{2} \rightarrow \mathrm{Z}=0.425$ & 0.425 & 0 & 0.425 \\
$\mathrm{X}_{1} \rightarrow \mathrm{Y}=0.285$ & 0.285 & 0 & 0.285 \\
$\mathrm{X}_{2} \rightarrow \mathrm{Y}=0.277$ & 0.277 & 0 & 0.277 \\
$\mathrm{Z} \rightarrow \mathrm{Y}=0.788$ & 0.788 & 0 & 0.788 \\
$\mathrm{X}_{1} \rightarrow \mathrm{Y}=0.285$ & 0.285 & $(0.228 \times 0.788)=0.180$ & 0.465 \\
$\mathrm{X}_{2} \rightarrow \mathrm{Y}=0.277$ & 0.277 & $(0.425 \times 0.788)=0.335$ & 0.612 \\
\hline
\end{tabular}

Sumber : Data diolah, 2016

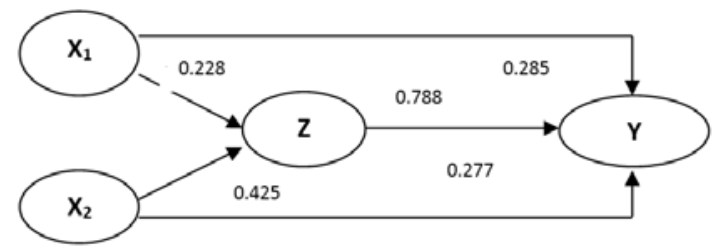

Gambar 1 . Analisis Jalur

Pengujian pengaruh tidak langsung pelatihan SDM $\left(\mathrm{X}_{1}\right)$ terhadap kinerja karyawan (Y) melaui disiplin kerja (Z) diperoleh koefisien regresi pelatihan SDM sebesar 0.285, koefisien regresi pengaruh tidak langsungnya yaitu $0.228 \times 0.788=$ 0.180 . Oleh karena koefisien tidak langsung pelatihan SDM lebih kecl dari koefisien pelatihan SDM langsung, maka dapat disimpulkan bahwa pelatihan SDM yang sebenarnya adalah langsung. Dengan kata lain, pelatihan SDM berpengaruh terhadap kinerja karyawannya tidak melalui disiplin kerja.

Pengujian pengaruh tidak langsung pengembangan $\operatorname{SDM}\left(\mathrm{X}_{2}\right)$ terhadap kinerja 
karyawannya (Y) melalui disiplin kerja (Z) diperoleh koefisien regresi pengembangan SDM langsung sebesar 0.277, kofisien regresi pengaruh tidak langsungnya yaitu $0.425 \times 0.0788=0.335$. Oleh karena koefisien tidak langsung pengembangan SDM lebih besar dari koefisien pengembangan SDM langsung, maka dapat disimpulkan bahwa pengembangan SDM yang sebenarnya adalah tidak langsung dengan kata lain pengembangan SDM berpengaruh terhadap kinerja karyawan melalui disiplin kerja.

\section{PEMBAHASAN}

Hasil analisis menunjukkan bahwa pelatihan dan pengembangan SDM mempunyai pengaruh signifikan terhadap disiplin kerja karyawan. Hal ini dapat diartikan, jika pelatihan SDM meningkat maka disiplin kerja akan meningkat pula. Manajemen disiplin kerja tetap menjadi masalah utama dalam hubungannya dengan karyawan dan merupakan sumber konflik di tempat kerja (Fenley, 1998). Untuk itu perusahaan harus memperhatikan indikatorindikator dalam pelatihan misalnya instruktur program pelatihan harus sesuai dengan kompetensi yang dibutuhkan, karyawan yang akan ikut pelatihan harus melalui assessment terlebih dahulu sehingga akan diketahui gap antara ekspektasi dan kinerja sesuai dengan kebutuhan, materi pelatihan yang sangat sesuai dengan tugas dan pekerjaan di lapangan. Materi yang disampaikan mampu menambah pengetahuan peserta pelatihan, program pelatihan dalam perusahaan dilaksanakan berkesinambungan dan pelatihan yang diselenggarakan memiliki sasaran yang jelas dan bermanfaat, maka disiplin kerja karyawan akan meningkat. Jika program pengembangan SDM meningkat maka perusahaan perlu meningkatkan soft skill, meiningkatkan kerja sama tim, membantu untuk memecahkan masalah operasional, meningkatkan kemampuan untuk melihat masalah dari berbagai arah, meningkatkan karir maka disiplin kerja karyawan akan mengalami peningkatan. Dan disiplin kerja berdampak pada produktifitas karyawan (Chirasha, 2013). Untuk meningkatkan disiplin kerja maka diperlukan program pelatihan dan pengembangan SDM. Hasil penelitian ini didukung oleh beberapa penelitian Zulaini (2010), dan Tahir, et.al. (2014) membuktikan bahwa pelatihan dan pengembangan SDM mampu meningkatkan disiplin kerja.

Hasil analisis menunjukkan bahwa pelatihan dan pengembangan SDM berpengaruh signifikan terhadap kinerja karyawan. Hal ini dapat diartikan, jika pelatihan dan pengembangan SDM meningkat maka kinerja karyawan akan meningkat pula. Pelatihan merupakan cara yang terorganisir dimana organisasi memberikan pengembangan dan meningkatkan kualitas baru dari yang sudah ada pada karyawan. Pelatihan dipandang sebagai suatu pendekatan sistematis dalam pembelajaran dan pengembangan yang meningkatkan individu, kelompok dan organisasi (Khawaja \& Nadeem, 2013). Untuk itu serangkaian kegiatan organisasi diarahkan ke penambahan pengetahuan atau keterampilan untuk peningkatan kinerja. Pelatihan juga berfungsi sebagai suatu tindakan intervensi untuk meningkatkan kualitas barang dan jasa dalam persaingan dan perbaikan dalam keterampilan teknis karyawan. Sedangkan pengembangan mengacu pada kegiatan yang mengarah pada perolehan pengetahuan atau keterampilan baru untuk tujuan pegembangan. Pengembangan karyawan adalah sebuah keharusan dan semakin kritis dan strategis bagi lingkungan bisnis saat ini (Hameed \& Waheed, 2011). Organisasi perlu investasi terus menerus dalam rangka mempertahankan karyawan serta keberhasilan organisasi (Khawaja \& Nadeem, 2013). Pelatihan telah meningkatkan produktivitas organisasi, bahkan tidak hanya itu tetapi juga memberikan kesempatan pembelajaran agar lebih kompeten. Berbagai penelitian menunjukkan dampak positif pelatihan dan pengembangan terhadap kinerja (Berge, et.al., 2002; Sultana, et.al., 2012; Devi and 
Shaik, 2012; Falola, et.al., 2014; Tahie, et.al., 2014; Asad and Mahfod, 2015; Atan \& Mahmood, 2015). Dengan pelatihan dan pengembangan mempengaruhi perilaku dan keterampilan karyawan yang akhirnya meningkatkan kinerja. Cara paling efektif memotivasi dan mempertahankan kualitas sumber daya manusia dalam sebuah organisasi dengan menggunakan pelatihan dan pengembangan (Atan \& Mahmood, 2015). Namun tujuan organisasi akan optimal jika sumber daya manusianya efektif dan efisien. Tenaga kerja akan efektif dan efisien jika program pelatihan dan pengembangan yang tepat disediakan organisasi. Pelatihan dan pengembangan perlu dirancang dan disampaikan untuk memenuhi kebutuhan semua karyawan tetapi juga meningkatkan kepuasan yang berdampak pada disiplin karyawan. Pengetahuan, keterampilan dan kemampuan penentu kinerja karyawan. Organisasi menghabiskan sejumlah dana dan waktu pada pelatihan dalam rangka untuk membantu pembelajaran karyawan agar kompeten (Noe, et.al., 2006).

Hasil analisis menunjukkan bahwa disiplin kerja mempunyai pengaruh terhadap kinerja karyawan. Hal ini dapat diartikan, jika disiplin kerja meningkat maka kinerja akan meningkat pula. Kinerja organisasi sebagai kemampuan organisasi untuk mencapai tujuannya dengan menggunakan sumber daya secara efektif dan efisien. Sementara disiplin diperlukan dalam banyak kesempatan. Organisasi perlu hati-hati untuk tidak menyakiti sumber daya yang melakukan pekerjaannya. Penanganan disiplin kadang menyebabkan kinerja berkurang baik terhdap individu, tim atau departeman. Manajemen untuk menghindari hal ini dengan menggunakan metode disiplin. Untuk itu manajer harus fokus pada koreksi perilaku tanpa emosional sehingga masalah disiplin tetap berjalan. Chien (2004) menyatakan bahwa keberhasilan pengelolaan keseimbangan antara disiplin dan kinerja merupakan kombinasi kepribadian antara manajer dan karyawan, situasi kerja tekanan serta tehnik manajemen yang efektif dan strateginya. Perlu ketrampilan yang unik, kombinasi tehnik resolusi konflik, kemampuan berempati, tingkat kecerdasan emosional. Tujuan dari disiplin kerja adalah untuk meningkatkan kinerja karyawan (Grote, 1995). Dalam mencapai kinerja maka perlu pengawas untuk berperan aktif membantu karyawan untuk memenuhi persyaratan minimum melalui manajemen kinerja (Halachmi, 2005).

Hasil analisis jalur diperoleh pelatihan SDM berpengaruh terhadap kinerja karyawan tidak melalui disiplin kerja. Pelatihan merupakan serangkaian aktifitas yang dirancang untuk meningkatkan keahlian-keahlian pengetahuan, pengalaman, ataupun perubahan sikap seorang individu. Hal ini sama dengan pemaparan dari Personalia STPP Magelang yang mengatakan bahwa pelatihan SDM akan berpengaruh lansung kepada kinerja karyawan tanpa melalui disiplin kerja, karena program pelatihan yang dilakukan lebih condong untuk melatih kemampuan tehnikal dari pada soft skill. Pelatihan lebih cenderung menggunakan untuk orientasi jangka pendek, pelatihan berpengaruh pada kinerja, jadi jika pelatihan yang dilakukan oleh perusahaan berhasil maka kinerja karyawan akan mengkat dengan sendirinya. Pembangunan SDM yang sebenarnya adalah tidak langsung dengan kata lain pengembangan SDM berpengaruh terhadap kinerja karyawan melalui disiplin kerja. Pengembangan merupakan rancangan pembelajaran untuk membantu pertumbuhan karyawan, memperbaiki kinerja karyawan pada pekerjaan mereka untuk memperbaiki posisi karyawan di masa yang akan dating (Tjeng, et.al., 2013). Inilah yang membedakan antara pelatihan dan pengembangan. Jika pelatihan lebih berorientasi jangka pendek maka pengembangan berorientasi untuk jangka panjang. Pengembangan biasanya berkaitan dengan peningkatan kemampuan intelektual atau emosional yang diperlukan untuk melaksanakan pekerjaan yang lebih baik. 


\section{Kesimpulan}

Pelatihan dan pengembangan SDM meningkatkan kinerja karyawan dan meningkatkan produktivitas organisasi. Pengembanan karyawan merupakan kunci untuk pembangunan berkelanjutan organisasi. Organisasi perlu karyawan yang mampu beradaptasi dengan pasar dunia yang selalu berubah. Berdasarkan hasil analisis menunjukkan bahwa pelatihan dan pengembangan SDM berpengaruh terhadap disiplin kerja dan kinerja karyawan, disiplin kerja karyawan berpengaruh terhadap kinerja karyawan Pelatihan SDM berpengaruh langsung terhadap kinerja karyawan tanpa melalui disiplin kerja karyawan dan pengembangan karyawan berpengaruh terhadap terhadap kinerja melalui disiplin kerja karyawan STPP Magelang

\section{Saran}

Manajemen STPP Magelang harus benar-benar lebih serius untuk tetap kontinyu melakukan peningkatan program pelatihan dan pengembangan SDM bidang penyuluhan persapian hasil produksi dari instansi setempat. Perlu dipertimbangan dan ditingkatkan juga tujuan program pelatihan dan pengembangan, materi pelatihan, dan siapa yang akan diberi pelatihan dan pengembangan SDM. Selain itu, juga harus meningkatkan lagi masalah disiplin kerja karyawan dan kinerjanya dengan cara memberikan program-program yang lebih efektif dan efisien. Penelitian lebih lanjut perlu menambah variabel penelitian dibidang manajemen misalnya lingkungan kerja, kompensasi, budaya organisasi, gaya kepemimpinan, komitmen organisasi dan lain sebagainya.

\section{DAFTAR PUSTAKA}

Ameeq, A. \& Hanif, F. (2013), Impact of Training on Employee's Development and Performance in Hotel Industry of Lakore Pakistan, Journal of Business Studies Quarterly, Vol.4,68-82

Asad, M. \& Mahfod, H. (2015), Training and development and its impact on thr employee's performance a study of agility Company-Kingdom, International Review of Management Business Research, Vol.4.,iss.3.,700712

Atan, J., Raghavan, S. \& Mahmood N.H.N. (2005), Impact of Training on Employees Job Performance: A Case Study of Malaysian Small Medium Enterprise, Review of Management, Vol.5, No.1/2, 40-50

Berge, Z., Verneil, M.D., Berge, N., Davis, L., \& Smith, D., (2002), “ The increasing scope of training and development competency “, Brenchmarking: An International Journal, Vol.9.,Iss. 1, 43-61

Brown, G. \& Read, A.R., (1984), Personnel and Training Policies-some lesson from western compnies, $h$ Long Range Planning , Iss.17, 48-57

Chen, T.Y., Chang, P.L., \& Yeh, C.W., (2004), A study off career needs, career development programs, job satisfaction and turnover intensity of $\mathrm{R}$ \& D personnel, Career Development International, Vol.9, No.4, 424-437

Chiaburu, D.S. \& Tekleab, A.G.(2005), individual and contectual influences on multiple dimensions of training effectiveness, Journal of European Industry Training, Vol.29, Iss.8.,604626

Chien, M.H. (2004), A Study to improve organizational performance, a view from strategic human resource management, Journal American Academic Business, Vol.4, 287

Chirasha, V., (2013), Management of Discipline for good performance : a theoretical perspective, online Journal of Social Sciences Research, Vol.2.,Iss.7., 214-219 
Colarelli, S.M. \& Montei, M.S. (1996), Some contextual influences on training utilization, The Journal of Applied Behavioral Science, Vol.32, Iss.3, 306322

Dessler, G. (2005), Human Resource Manajement, $10^{\text {th }}$ ed., Pearson Prentice Hall, USA

Devi, V.R. \& Shaik, N.(2012), Training \& development-a jump starter for employee performance and organizational effectiveness, International Journal of Social Science \& Interdisciplinary Research, Vol.1, Iss.7, 202

Diab, S.M.\& Ajlouni, M.T., (2005), The Influence of Training on Employee's Performance, Organizational Commitment, and Quality of Medical at Jordanian Private Hospitals, International Journal of Business and Management, Vol.10, No.2

Engelbrecht, Amos S., Johanita, S. \& Louis, V.D.B. (2008), Perceived fairness of disciplinary procedure in the public service sector: an exploratory study, $S A$ Journal of Human Resource Management, Vol.6, No.2, 1-8

Falola, H.O., Osibanjo, A.O., \& Ojo, S.I., (2014), Effectiveness of training and development on employees performance and organization competitiveness in the Nigerian Banking Industry, Bulletin of the Transilvania University of Brasov.

Fenley, a., (1998), Models, styles and metaphors: understanding the management of discipline, Employee Relation, Vol.20, 353

Ghozali, L., (2011), Aplikasi analisis multivariate dengan program SPSS, Badan Penerbit Universitas Diponegoro, Semarang.
Grote, D. (2006), Discipline without punishment: the proven strategy that turns problem employees into superior performances, Amazon, American Management Association.

Guest, D.E. (2011), Human resource management and performance: still searching for some answers, Human Resource Management Journal, Vol.21, Iss., 1, 3-13

Halachmi, A. (2005), Performance measurement is only one way managing performance, Internatinal Journal Production Performance Management, Vol.54, 448-465

Hameed, A. \& Waheed, A. (2011), Employee development and its affect on employee performance a conceptual framework, International Journal of Business and Social Science, Vol.2, No. 13., 224

Hanawai, Hadari, (2005), Manajemen Sumber Daya Manusia untuk bisnis yang kompetitif. Gajah Mada University Press.207-291

Harlie, M. (2012), Pengaruh disiplin kerja, motivasi dan pengembangan kerier terhadap kinerja pegawai negeri sipil pada pemerintah Kabupaten Tabalong di Tanjung Kalimantan Selatan, www. Jurnaljam.ub.ac.id/index, php/jam/article/fiewFile/473/511

Hollenbeck J.R., Derue, D.S., Guzzo, R. (2004), Bridging the gap between I/O research and HR practice: improving team composition, team training and team task design, Human Resource Management Journal, Vol. 4., 353-366

Jie, S. \& Roger, D.(2006), Training and management development in Chinese multinational enterprices, Employee Relations, Vol. 28, Iss.4. 342-362 
Khawaja \& Nadeem (2013), Training and development program and its benefits to employee and organization: A conceptual study, European Journal of Business and Management, Vol.5.,No.2

Kreitner, R. \& Kinicki, A. (2007), Organizational Behavior, $7^{\text {th }}$ edition, McGrowHill Irwin, Boston.

Mangkunegara, A.P., (2013), Manajemen Sumber Daya Manusia Perusahaan, Penerbit PT Remaja Rosdakarya, Cetakan ke sebelas, Bandung.

Noe, R.A., Hollenbeck, J.R., Gerhart, B. \& Wright, P.M. (2006), Human Resource Management, Gaining Competitive.

Pfeffer J., (1994), Competitive Advantage through People, Harvard Business School Press, Boston.

Rivai, Veithzal dan Basri (2005), Performance Appraisal: Sistem Yang Tepat Untuk Menilai Kinerja Karyawan dan Meningkatkan Daya Saing Perusahaan, Raja Grafindo Persada, Jakarta.

Ronald, S.R. (2006), Human Resource Development: Today and Tomorrow, Information Age Publishing Inc, USA

Rowden, R.W. \& Conine Jr, C.T. (2005), The impact of workplace learning on job satisfaction in small US commercial banks, Journal of Workplace Learning, Vol.17, Iss.4., 215-230

Sims, R. (2002), Organizational Success through Effective Human Resources Management, Westport CT: Quorum Books

Soss, J., Fording, R. \& Schram, S. F. (2011), The organization of discipline: from performance management to perversity and punishment, Journal of Public Administration Research and Theory, Vol.21, 203-232

Sultana, A., Irum, S., Ahmed, K., \& Mehmood, N.(2012), Impact of training on employee performance; a study of telecommunication sector in Pakistan . Interdisciplinary Journal of Contemporary Research in Business, Vol.4, Iss.6.,646-551

Suwarsih, I, (2005), Hubungan Anatara Pelatihan dan Kepuasan Kerja dengan Produktivitas Kerja Karyawan Produksi PT Tirta Investama Pabrik Citeureup Bogor. Tesis. Program Pascasarjana, Universitas Muhammadiyah Prof. Dr. Hamka. Hal: 12-33

Tahir, N., Yousafzai, I.K., Jan, S., \& Hashim, M.(2014), The impact of training and development on employees performance and productivity a case study of United Bank Limeted Peshawar City, KPK, Pakistan, International Journal of Academic Research in Business and Social Sciences, Vol.4, No.4, 86-98

Tjeng, E., Said, L.R., \& Wandary, W. (2013), Pengaruh program pelatihan dan pengembangan terhadap kinerja karyawan pada PT Bank Central Asia Tbk (Study Pada Frontliner Bakti BCA Keu Banjarmasin), Jurnal Wawasan Manajemen, Vol.1, Nomor.3.

Tjahjono, H.K. (2005), Praktik-praktik manajemen SDM strategic: pengujian universakistik dan kontijensi dalam menjelaskan kinerja organisasional. Jurnal Bisnis dan Ekonomi Kinerja, 9(2):123-134.

Tsai P., Yen, C.Y., Huang, L.(2007), A study on motivating employees learning commitment in the post downsizing era: job satisfaction perspective, 
Journal of Word Business, Vol.42, 157-169

Zulaini, N.R. (2010), Pengaruh pelaksanaan pelatihan terhadap disiplin kerja karyawan pada Yayasan Kesejahteraan Pendidikan dan Perumahan, Skripsi, repository, widyatama ac.id/xmlui/ handle/123456789/2584 